\title{
Microscopic study of potential toxic effects of monosodium glutamate on liver of chicken embryos aged 16 days
}

\author{
Fawzyah A. Al-Ghamdi®
}

\begin{abstract}
Background: This experimental study aimed to determine the changes caused by monosodium glutamate (MSG) on morphology and histology of liver of chicken embryos aged 16 days of incubation. In this research, 50 fertilized eggs were used. They were divided into two equal groups, one group was used as control with normal liver structure, while the other group (MSG) was treated with MSG in 0 day of incubation $(0.1 \mathrm{ml} / \mathrm{egg})$.

Results: The results showed many harmful effects on hepatic cells, blood sinusoids, and bile ducts in MSG group. These changes included alterations in nuclei conformation and nuclear envelope. Chromatin distribution was associated with increased electronic intensity. Also, there were rupture in smooth endoplasm systems and malfunction of mitochondria and Golgi apparatus, with increased lysosomes and lipid droplets.

Conclusions: This study concluded that MSG had severe toxic effects on liver structure if it was given in preconception period as this period is considered critical for liver growth (organogenesis).
\end{abstract}

Keywords: Monosodium glutamate, Taste improvers, Chicken embryos, Liver, Electron microscope

\section{Background}

The liver normally consists of parenchymal cells and nonparenchymal cells. The parenchymal cells or the hepatocytes have an envelope that consists of two parallel membranes. These hepatocytes contain mitochondria (Mi) surrounded by rough endoplasmic reticulum (RER). The ribosomes $(\mathrm{R})$ of these cells are free and not attached to mitochondrial membranes [1]. The non-parenchymal cells include Kupffer, satellite cells, and the endothelial cells (EC) that line the blood sinusoids (BS) [2].

Monosodium glutamate is one of the most commonly added chemicals to foods. It is the salt form of glutamic acid, a non-essential amino acid, with unique flavorenhancing quality [3]. MSG is considered as an excitotoxin that alter normal neurotransmission functions in animal biological systems [4]. It results in harmful effects on the body organs such as brain damage, retinal

Correspondence: dr_fawzyah1@hotmail.com

Department of Zoology (Embryology), College of Science, University of Jeddah, Jeddah 22246, Kingdom of Saudi Arabia degeneration, and hepatic toxicity [5]. Many studies showed that MSG can cross the placenta and reach the fetus if it was injected in pregnant animals [6]. Some studies reported that MSG has oxidative effects on various organs [7] and that it increases the risk of certain cancers [8]. The effects of food additives may be immediate or long term. Immediate effects include headache, change in energy levels, alteration in behavior, or reduced immune response. Long-term effects occur with constant exposure to the food additives and include increased risk of cancer [9]. There are many studies that dealt with the effects of MSG, but those that dealt with its effects on fetuses are few, and those dealt with the effects of its consumption before pregnancy on embryonic formation are extremely limited.

This experimental study aimed to determine the changes caused by MSG on morphology and histology of the liver of chicken embryos aged 16 days of incubation, to find out its harmful effects on liver organogenesis. 


\section{Methods}

\section{The experimental animals}

Fifty chicken eggs were used in this experimental study. Their mean weight was 60-62 g. They were obtained immediately at the time of laying by the chicken and prior to their incubation from a farm in Jeddah city in Western region of Saudi Arabia. Chicken embryos were used in this experimental research as they are highly sensitive to any nutrition deficiency provided to them and they develop the congenital anomalies that produced by different drugs on mammalian embryos.

\section{Materials}

\section{Monosodium glutamate}

MSG is white crystalline powder, fast-soluble in water, supplied by the Ayaz Packaging and Food Packaging Company in Jeddah.

\section{Experimental groups}

In this study, 50 eggs were used and divided equally into two main groups. The first group (control, C) included 25 eggs, used to study the composition and normal growth of liver. The second group (MSG group) included 25 eggs treated with MSG on 0 day of incubation by making two holes inside the air sac [10]. The eggs of the both groups were incubated at $37.5^{\circ} \mathrm{C}$. Liver samples were prepared for electron microscopic examination at day 16 to compare between the liver structure in the control and MSG-treated group [11, 12].

\section{The dose used of monosodium glutamate}

Each egg was injected with an effective dose of $0.1 \mathrm{ml}$ of monosodium glutamate solution inside the air sac before incubation [13].

\section{Results}

The normal growth of liver (control group, C)

The liver samples of the control group at 16 days of incubation showed that the liver consists of polygonal parenchymal cells that mostly appeared irregular with 4-6 sides, and non-parenchymal cells including Kupffer cells (KC) and EC that line BS (Fig. 1C-1, C-2) According to the electronic density, the hepatic cells were divided into two types: dark hepatocytes (DC) and pale hepatocytes (PC). The DC are characterized by the presence of many cytoplasmic organelles (Fig. $1 \mathrm{C}-1, \mathrm{C}-2)$. The samples of this study showed that $\mathrm{N}$ of hepatocytes are large and different in size from one cell to another, and that there are two types of chromatin inside them: heterochromatin (HC) and euchromatin (ECr). Each $\mathrm{N}$ was surrounded by nuclear envelope (NE) encrusted with holes or nuclear pores (NP) (Fig. 1C-1, C-2, C-3, C-4, C-5, C-6).
The studied sample showed that the surface of hepatocytes is divided into three parts: the first part faces the bile ducts $(\mathrm{BC})$, the second part faces the adjacent hepatic cells, and the third part faces Disse space (DS). Also, there were desmosomes (D) and tight junction (TG) between cells (Fig. 1C-7, C-8, C-9).

This study showed that the cytoplasm contains cellular organelles, which included Mi, G, RER, SER, LY1, LY2, multivesicular bodies (MB), and peroxisomes (P) (Fig. 1C1, C-2, C-3, C-4, C-5, C-6, C-7, C-8).

In this study, the hepatic cell was found to contain $G$ that consist of tubular or flat membranous cisternae, with surface vesicles (V) and large gaps. These $G$ have a convex outer face or formed face (FF) and another concave or mature face (MF). They are often located around the nucleus and alongside areas of adjacent liver cells near $\mathrm{BC}$ and the surface of the hepatocyte facing sinusoidal cavities (Fig. 1C-6, C-7, C-8).

The Mi within the hepatic cells of this study samples appeared as multiform (circular, oval-to-long), multisized and moderately dense organelles, which have two membranes separated by a space. Their outer membrane is semi-permeable and contains enzymes, while the inner membrane is folded inwards forming cisternae. Their inner cavity is filled with the mitochondrial matrix. A close spatial correlation between $\mathrm{Mi}$ and coarse endoplasmic network was noted (Fig. 1C-1, C-2, C-3, C-4, C5, C-6, C-7, C-8).

This study samples showed that there are lysosomes (LY) inside the liver cells. These LY differ in size, number, position, and electron density from one liver cell to another and they are more frequent in the areas of cytoplasm adjacent to BC and G. There are many forms of these LY including LY1 and LY2 in addition to P (Fig. 1C3, C-4, C-5, C-6, C-7, C-8) and MB (Fig. 1C-2, C-3, C-8).

The GL particles appeared as asteroid granules, which are electronically dense and collected in the cytoplasm near SER (Fig. 1C-2, C-8).

The LD within the cytoplasm of the hepatic cells of the samples appeared as rounded structures of variable sizes and surrounded by thin membrane (Fig. 1C-7, C-8).

In our samples, $\mathrm{BC}$ appeared as an area around which many adjacent hepatocytes were clustered. These BC were bounded only by the plasma membranes of adjacent liver cells which have been modified to form small microvilli (MV) that extend into the canaliculi. The plasma membranes close to $\mathrm{BC}$ are bound by tight bonds which include the zone of obstruction $(\mathrm{ZO})$, the zone of attachment (ZA), and the desmosomal junctions (Fig. 1C-7, C-8)

The hepatic cell clusters in this study samples were separated by BS, which were large and lined with EC and $\mathrm{KC}$. The EC lining BS are separated from liver cells by a space called DS (Fig. 1C-1, C-9). 


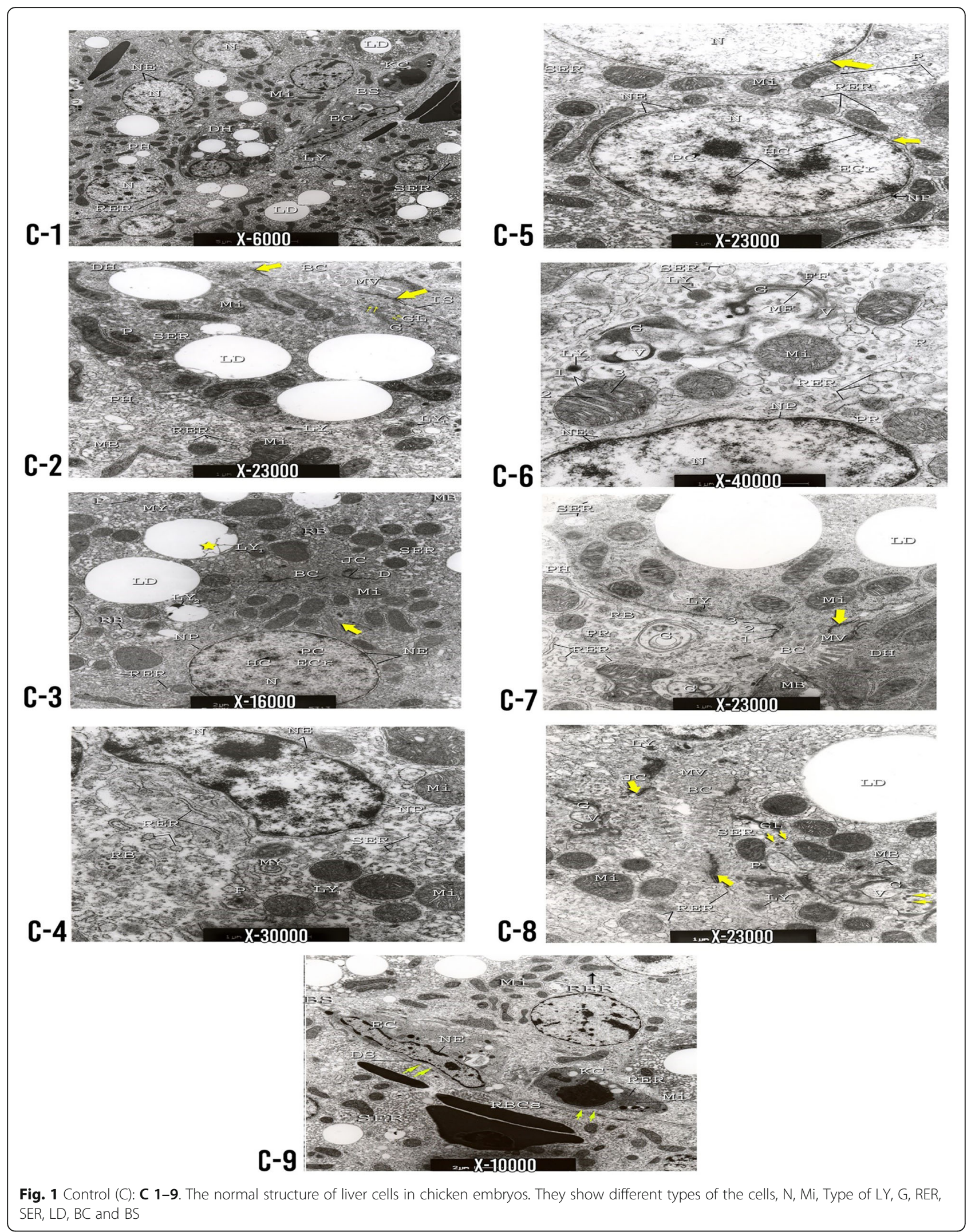


The effect of monosodium glutamate on the structure of the liver of chicken embryos (MSG group)

Examination of samples from the liver aged 16 days of MSG group by electron microscope showed many structural changes and histopathological degradation of liver cells including changes in $\mathrm{N}$ such as irregular NE, dilatation of NP, or increased HC. Also, many $\mathrm{N}$ have lost their electron density, and others showed marked derangement of NE either partially or totally. Moreover, there was a space between $\mathrm{N}$ and cytoplasm in some places called the nuclear space, or there was a dilation between the two layers of NE. Many N were seen at cells edges (nuclear margination) (Fig. 2 T-3, T-4).

In this study, Mi appeared to have irregular envelope with abnormal cristae and high electronic density due to derangement of its components (mitochondrial envelope, cristae, and mitochondrial matrix). Some Mi appeared as dark or decaying bodies with difficult differentiation of their internal contents (Figs. $2 \mathrm{~T}-3, \mathrm{~T}$ 5, T-6 and 3 T-7).

This study samples also showed disruption and disorganization of RER, where they lost their parallel cisternae and showed fragmentation, vacuolation, dilation, or degradation in some parts (Fig. 2 T-3, T-4, T-6).

The SER observed in this study samples showed proliferation of its units and disturbance of its distribution. Also, there was a spatial correlation between SER and GL (Figs. 2 T-5, T-6 and 3 T-8, T-12).

In the current study, it was difficult to see $\mathrm{G}$ in many of the treated cells, and even if it was seen, it appeared as either atrophic or hypertrophied bodies with expanded or vacuolated membranes (Figs. 2 T-5 and 3 T-9).

It was observed also in this study samples that there is variable distribution of LY1 and LY2 as well as P inside the treated cells. The P appeared as clusters, and some of which contained reaction products. Also, LY2 appeared attached to LD (Figs. 2 T-6 and 3 T-9).

The results of this study showed that $\mathrm{BC}$ appeared as dilated areas with short few MV, while there was expansion and increase in the number of desmosomal junctions surrounding multiplied BC (Figs. 2 T-5, T-6 and 3 T-10).

In this study, BS were extensive with destruction of their walls and alteration of lining cells, EC and KC. The sinusoidal space was filled with RBCs, cellular residues, and collagen fibers (Figs. 2 T-1 and 3 T-11).

It was observed that there is excessive fatty infiltration in the cells lining BS, where LD were often related to LY2 and they were either separate or merged with each other. These LD variable in size and there was increase in their number within MSG treated liver cells (Figs. 2 $\mathrm{T}-1, \mathrm{~T}-2, \mathrm{~T}-6$ and $3 \mathrm{~T}-10, \mathrm{~T}-12$ ).

This study showed several collagen fibers in the connective tissues and in between liver cells; however, the GL particles were few (Figs. 2 T-5, T-6 and 3 T-8, T-12).
In this study, there was expansion of the intercellular (IS) spaces and it was associated with expansion of BS, which indicates that the first response to cellular damage was cell expansion (Figs. 2 T-2, T-4 and 3 T-11).

\section{Discussion}

The normal growth of liver (control group, C)

This study revealed the general structure of the liver, which is formed of DC and PC. The DC are characterized by the presence of many cytoplasmic organelles and relatively variable nuclei $(\mathrm{N})$ with dark chromatin. However, PC contain more abundant RER and free $\mathrm{R}$ and their $\mathrm{N}$ are true with equally distributed chromatin.

This agrees with Bourne [14] who also described that the liver contains $\mathrm{KC}, \mathrm{EC}$ that line $\mathrm{BS}$, and parenchymal cells which are divided into DC and PC. Also, Medlock and Haar [15] and Abdel-Fatah [16] stated that cytoplasm of DC contains large number of Mi, RER, primary lysosomes (LY1), secondary lysosomes (LY2), lipid droplet (LD), and Golgi apparatus (G), with less smooth endoplasmic reticulum (SER).

The $\mathrm{N}$ of hepatocytes are large, surrounded by $\mathrm{NE}$, and contain two types of nuclear chromatin (ECr and $\mathrm{HC})$. In agreement with our results, Abdel-Fatah [16] and Bruni and Porter [17] reported that $\mathrm{N}$ contain two types of chromatin, $\mathrm{HC}$ and $\mathrm{ECr}$, and that they are surrounded by double layered nuclear membrane that contains many NP spread over variable distances.

All the cytoplasmic organelles appeared in the liver cells of our study including RER and R. This is consistent with Moule [18] who recorded that the liver cells at the age of 8 days of incubation showed RER and $\mathrm{R}$ which are scattered in the cytoplasm. Bruni and Porter [17] reported that there is difference in the position of endoplasmic reticulum (ER) not only from one liver cell to another, but also in a single liver cell, which indicated that ER is not a standard compound, but there may be changes in its direction, position, or composition. They also showed that SER are distributed in areas of the cell rich in glycogen (GL).

The $\mathrm{G}$ appeared to have two faces (FF and MF) and contain. It was located around the $\mathrm{N}$, near $\mathrm{BC}$ and the BS. This description was corroborated by Abdel-Fatah [16], Johnson [19], Al-Yousuf [20], and Burkitt et al. [21] who described $\mathrm{G}$ as a group of cisternae and parallel V with many gaps, and that they have two sides, convex and concave, and lie very close to the $\mathrm{N}, \mathrm{BC}$, and BS.

The Mi appeared with variable shapes and sizes. It had two membranes separated by a space, where the inner membrane was folded inwards to form cisternae. It was spatially associated with the RER. This is consistent with Bruni and Porter [17] who reported that Mi are closely related to RER. Al-Yousuf [20] and Burkitt et al. [21] added that $\mathrm{Mi}$ are variable in size but mostly rectangular, and their number may reach up to 2000 per cell. 


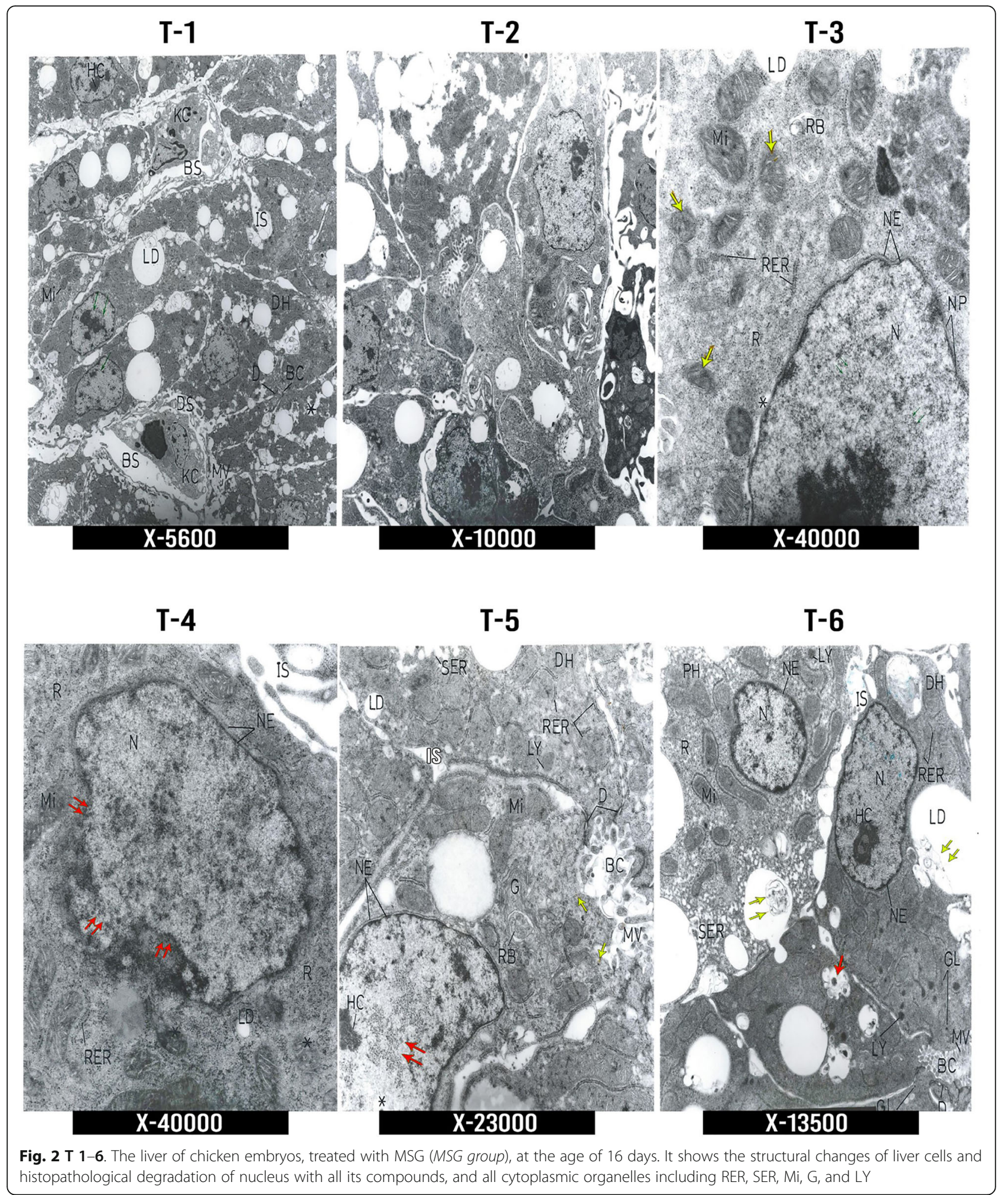

The lysosomes appeared in their various types which include $\mathrm{Ly}_{1}, \mathrm{Ly}_{2}, \mathrm{P}$, and $\mathrm{MB}$. This agrees with Bruni and Porter [17] and Burkitt et al. [21] who reported that LY1 appeared as membrane-bounded organelles, variable in size and shape, and contained undifferentiated granular materials, while LY2 were more variable in their 


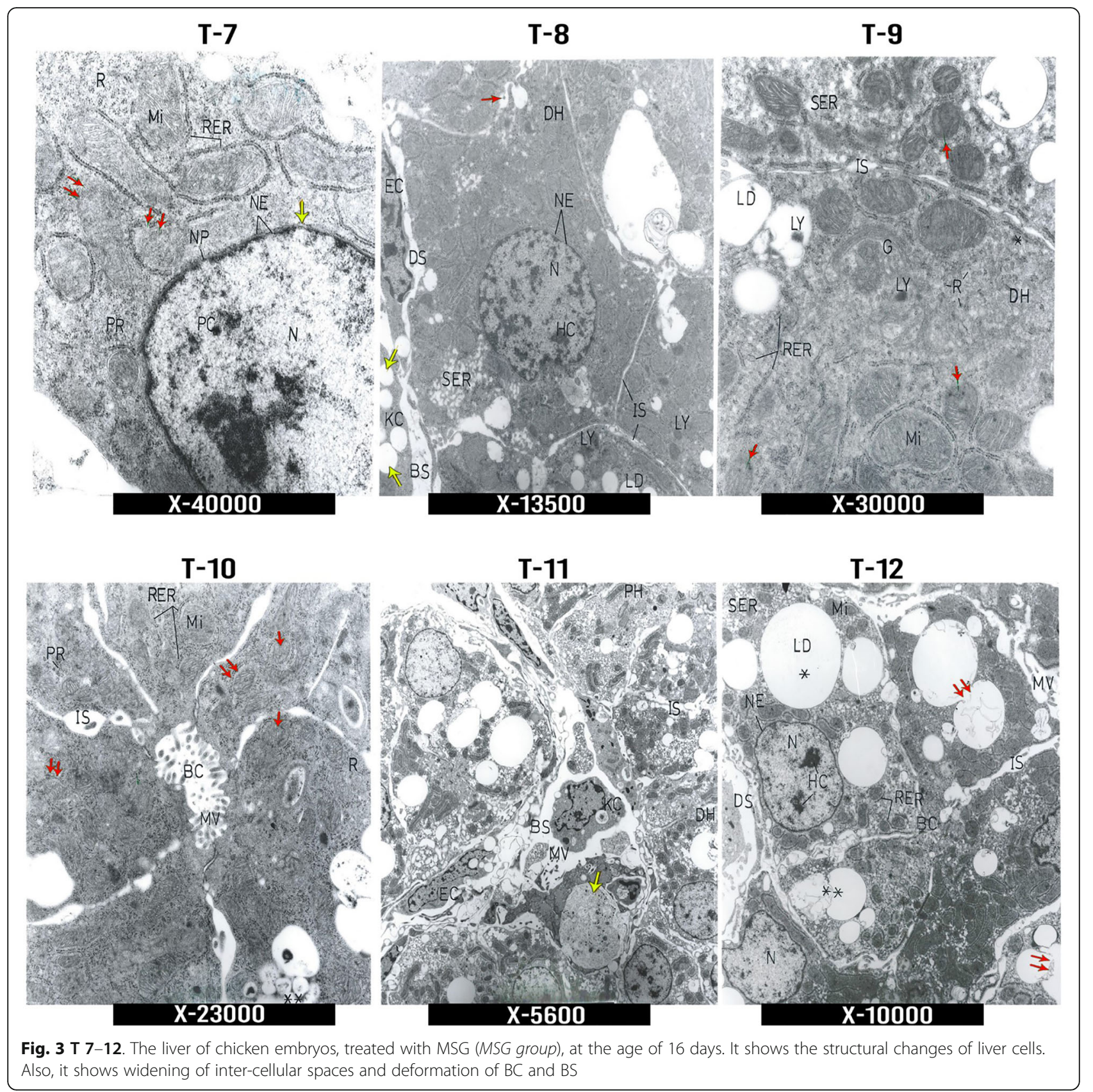

appearance and some of them were very dense. Moreover, $\mathrm{P}$ appeared as small spherical membrane bounded structures.

Glycogen particles were seen collected in the cytoplasm near SER. Also, Han and Holmsted [22] noted that SER are closely related to GL particles. However these particles are rare or completely absent in areas of RER and/or R.

LD of variable sizes were detected in the liver cells of this study. This agreed with Abdel-Fatah [16] and Mahmoud [23] who described LD as multi-form fatty globuli of variable sizes.
$\mathrm{BC}$ regions were seen between adjacent cells. The plasma membranes of the cells close to $\mathrm{BC}$ were bound by tight bonds which include (ZO), (ZA), and D junctions. This result was supported by Han and Holmsted [22] who reported that $\mathrm{BC}$ are areas between the membranes of adjacent hepatocytes.

In this study samples, the hepatic cells were separated by BS lined with EC and KC. The EC lining BS were separated from liver cells by a space called DS. Bruni and Porter [17] explained that blood fluids pass freely through EC of BS to DS to be in direct contact with the 
hepatic cells facilitating the exchange of important substances between blood and hepatic cells.

\section{The effect of monosodium glutamate on the structure of the liver of chicken embryos (MSG group)}

Many structural changes had occurred in the liver cells after exposure to MSG. The changes that occurred in N included irregular NE, dilatation of NP, or increased HC. Moreover, many $\mathrm{N}$ have lost their electron density. This agree with Farhoud [24] and Abdel-Fatah [16] who reported that the changes occurred in $\mathrm{N}$ of liver cells of chicken embryos included increase in $\mathrm{HC}$ amount and disturbance of its distribution. Also, the NE became irregular and interrupted with expansion of space between its two layers and dilatation of NP with some connection between nuclear material and cytoplasm.

Major changes have occurred in mitochondria where their envelope became irregular and their components get degraded. These results are supported by AbdelFatah [16] who reported appearance of abnormal Mi, which were either decayed, partially or completely atrophied with disruption of its components, increase of its density, and deposition of decayed materials inside it. Hummdi [25] indicated that the marked changes that occurred in $\mathrm{Mi}$, including its atrophy or deposition of decayed materials inside it, resulted in loss of its functions and damage of the cell.

The RER showed fragmentation, vacuolation, and dilation in some of its parts. This agrees with the results of Abdel-Fatah [16] who confirmed that one of the most prominent observations on RER was its appearance either fragmented or vacuolated with disturbances in its shape. Also, it sometimes appeared decayed and free of R.

SER showed proliferation of its units and disturbance of its distribution. The proliferation of SER might be explained by its ability to detoxify MSG. This is consistent with Moody and Reddy [26] and Ahmed [27] who reported a close association between the proliferation of SER and the degree of cell damage. Ayman et al. [28] explained the increase in SER proliferation as a rapid response to the adverse effects on cells and that it is associated with an increase in enzymes' activity to increase the cells ability to detoxify harmful substances.

The G appeared as either atrophic or hypertrophied bodies with expanded or vacuolated membranes.

This can be explained by that $\mathrm{G}$ are organelles characterized by its rapid decay and that they are difficult to be detected. This observation was supported by AbdelFatah [16] who reported that $G$ were difficult to be distinguished. They were found inside hepatic cell in the form of either atrophied or hypertrophied bodies and often appeared near the nucleus or the edges of hepatic cell adjacent to $\mathrm{BC}$.
Our samples showed variable distribution of LY1, LY2, and $\mathrm{P}$ inside the treated cells, and some of them appeared attached to LD or contained reactions products. This agrees with Ahmed [27] and de Duve [29] who reported increase in LY numbers and hydrolysis with release of LY enzymes such as phosphatase secondary to cell injury.

BC appeared as dilated areas with short MV. Also, there was decrease in their numbers and increase in the number of desmosomal junctions surrounding the multiplied BC. This is supported by Abdel-Fatah [16] results which showed that during acute injury of hepatic cells, the D appeared wide, proliferated with distortion of their composition.

BS were extensive with destruction of their walls and enlargement of their lining cells. The BS cavity appeared filled with RBCs, cellular residues, and collagen fibers. This agrees with the observations of Hassan [30] and Cotran [31] who attributed the enlargement of $\mathrm{KC}$ to defensive activity of these cells against poisoning. AbdelFatah [16] and Eid et al. [8] emphasized that BS appeared dilated and more extended with presence of many cellular residues, collagen fibers, broken MV, and dead cells inside their cavities.

There was variable sized cytoplasmic vacuoles in MSG-treated liver cells as reported also by Pfeifer and Bannasch [32], Tuchweber et al. [33], and Abbasi et al. [34]. These vacuoles may be caused by mitochondrial swelling or decomposition of mitochondrial remnants as reported by Takano et al [35], or due to enzyme digestion of cell organelles due to cell injury as reported by Cotran [31], Biondo-Simões et al. [36], Aldana et al. [37], and Luty et al. [38]. Also, Bourne [14] reported that formation of these vacuoles may be a part of defensive mechanism to prevent interference with cell vital activities or may be due to sinusoidal dilatation as reported by Shibayama et al. [39]. The membrane surrounding these vacuoles showed the same enzymatic activity of liver cell membrane; so many scientists believe that they are indentations from cell membrane. Tuchweber et al. [33], Takano et al. [35], and Burkitt [40] reported that these vacuoles are LD that accumulated secondary to obstruction of fatty acids metabolism by liver cells.

There were excessive collagen fibers in connective tissues and between liver cells of our samples. This agrees with Farhoud [24] who reported large amount of collagen fibers in the base plate of the mouse at 3rd week of MSG injection. Awad [41] added that the amount of collagen fibers in connective tissues barriers and among cells was more or less than control sample on days 1012 of preparation, and as growth advanced at 15-18 days of preparation, there was an increase in the amount of collagen fibers in barriers between cells. 
Also there were a few GL particles in the MSG-treated cells and this was also observed by Dixon et al. [42] who found depletion of GL from cells.

There was expansion in the intercellular (IS) spaces with associated expansion of BS. This was confirmed by Young [43] who reported that intercellular expansion is a common phenomenon associated with BS expansion and resulted from fluids accumulation between cellular components as collagen fibers.

The changes that occur in the cellular functions as a result of the toxic compounds include changes in cell membrane permeability and affection of movement of materials to and from the cells. They also include changes in cellular enzymatic activities, changes in cellular division rates, changes in DNA and protein synthesis, changes in cell respiratory processes rate, and changes in energy molecules availability. Al-Ghamdi [44] reported that the harmful effects of the toxic chemicals may be caused by binding of these toxic chemicals to the biomolecules. This binding may be reversible or irreversible leading to apoptosis or affection of the cellular structure.

The effects of MSG on liver tissues can be explained by its ability to infiltrate and cross blood-brain-barrier due to incomplete development and weakness of this barrier, especially in fetuses, newborns and infants, causing high toxicity followed by defects in growth and differentiation of various tissues and cells. It also induces neurotoxicity by interacting with $\mathrm{N}$-methyl-D-aspartate (NMDA) receptors causing inhibition of membrane proteins formation and change of the cell membrane organization causing cell destruction.

Burkitt et al. [21] explained that cellular decomposition occurs secondary to the inflammatory reactions of body's immune system against damage caused by chemical compounds, parasitic and viral infections, and harmful substances.

Overstreet et al. [45] concluded that MSG had ability to cross epithelial cells membranes in peritoneal cavity and break down into sodium and glutamic acid where some of glutamic acid is excreted and the rest is converted into glutamate and during this process, the liver cells try to repair the damage occurred in their organelles. With the high percentage of glutamate, the liver cells cannot excrete or detoxify it, so a series of hemolytic changes occurs in liver gradually and finally death of the liver cells occur. Anbarkeh et al. [7] reported that cytotoxicity (apoptosis) may occur due to many factors as DNA damage, loss of survival signals, or oxidative voltage. Giorgio et al. [46] said that apoptosis occurred when the cell was severely injured as cell swells and ruptures and these effects occur because the injury prevents the cell from adjusting balance of its fluid and ions that are usually pumped out of the cell but in case of infection, they flow into cells.
Anindita et al. [47] and Hassan et al. [48] reported that MSG administration resulted in significant changes in apoptotic biomarkers as programmed cell death protein-1 related to liver damage and decrease in hepatic cell thickness.

\section{Conclusions}

These results suggest that MSG plays a role in cellular oxidative stress, which in turn lead to cell death, increased apoptosis, DNA and RNA destructions, and lack of protein production which is necessary for receptors formation. Lack of cells thickness and disturbance of the rate of their division and proliferation caused delayed growth and disruption of liver formation in general.

\section{Abbreviations}

BC: Bile ducts; BS: Blood sinusoids; D: Desmosomes; DC: Dark hepatocytes; DS: Disse space; EC: Endothelial cells; ECr: Euchromatin; ER: Endoplasmic reticulum; FF: Formed face; G: Golgi apparatus; GL: Glycogen; HC: Heterochromatin; KC: Kupffer cells; LD: Lipid droplets; LY: Lysosomes; LY1: Primary lysosomes; LY2: Secondary lysosomes; MB: Multivesicular bodies; MF: Mature face; Mi: Mitochondria; MSG: Monosodium glutamate; MV: Microvilli; N: Nuclei; NE: Nuclear envelope; NP: Nuclear pores; P: Peroxisomes; PC: Pale hepatocytes; R: Ribosomes; RER: Rough endoplasmic reticulum; SER: Smooth endoplasmic reticulum; TG: Tight junction; V: Vesicles; ZA: Zone of attachment; ZO: Zone of obstruction

\section{Acknowledgements}

This project did not receive any specific grant from funding agencies.

\section{Author's contributions}

FAA made the design of the work, the conception of the idea, acquisition, analysis and interpretation of data, and finally the revision and final approval of the manuscript.

Funding

This research is completely funded by the author.

Availability of data and materials

Not applicable

\section{Declarations}

Ethics approval and consent to participate

Not applicable

Consent for publication

Not applicable

\section{Competing interests}

The author declares that she has no competing interests.

Received: 4 January 2021 Accepted: 4 May 2021

Published online: 15 May 2021

\section{References}

1. Ward DB, Pollak J (1967) The phospholipid composition of embryonic chick liver microsomes. Biochem J 104(3):861-865. https://doi.org/10.1042/bj104 0861

2. Kwak KA, Cho HJ, Yang JY, Park YS (2018) Current perspectives regarding stem cell-based therapy for liver cirrhosis. Can J Gastroenterol 2018:4197857

3. Quines CB, Rosa SG, Da Rocha JT, Gai BM, Bortolatto CF, Duarte MM, Nogueira CW (2014) Monosodium glutamate, a food additive, induces depressive-like and anxiogenic-like behaviors in young rats. Life Sci J 107(12):27-31. https://doi.org/10.1016/j.lfs.2014.04.032

4. Mahaliyana A, Fasmina M, Alahakoon A, Wickrama G (2016) Toxicity effects of monosodium glutamate (MSG) on embryonic development of zebrafish 
(Danio rerio); a promising model to study excitotoxins. Int J Sci Res 6(3): 229-234

5. Foran L, Blackburn K, Kulesza RJ (2017) Auditory hindbrain atrophy and anomalous calcium binding protein expression after neonatal exposure to monosodium glutamate. Neuroscience 344:406-417. https://doi.org/10.101 6/j.neuroscience.2017.01.004

6. Park JS, Choi MA, Kim BS, Han IS, Kurata T, Yu R (2000) Capsaicin protects against ethanol-induced oxidative injury in the gastric mucosa of rats. Life Sci J 67(25):3087-3093. https://doi.org/10.1016/50024-3205(00)00890-0

7. Anbarkeh FR, Baradaran R, Ghandy N, Jalali M, Nikravesh MR, Soukhtanloo M (2019) Effects of monosodium glutamate on apoptosis of germ cells in testicular tissue of adult rat: an experimental study. Int J Reprod Biomed 17(4):261-270

8. Eid RA, Al-Shraim M, Zaki MS et al (2019) Vitamin E protects against monosodium glutamate-induced acute liver injury and hepatocyte ultrastructural alterations in rats. Ultrastruct Pathol 43(4-5):199-208. https:// doi.org/10.1080/01913123.2019.1673860

9. Dar H, Shivani C, Karishma S, Azam Z, Anupam R (2017) Immunomodulatory effects of food additives. Int J Immunother Cancer Res 3(2):19-31

10. Allam H, Noor-El-Din M, Radwan A, El-Naggar M (1976) A new method and repeated injection of drugs in ova in chick embryo. Al-Azhar Med J 5:311317

11. Ragab AH (1970) The structure and innervation of tortoise muscle spindles (Dissertation) Durham University

12. Reynolds ES (1963) The use of lead citrate at high pH as an electronopaque stain in electron microscopy. J Cell Biol 17(1):208

13. Al-Qudsi F, Al-Jahdali A (2012) Effect of Monosodium Glutamate on chick embryo development. J Am Sci 8(10):499-509

14. Bourne G (2012) Cytology and cell physiology, 3rd edn. Academic Press, Cambridge

15. Medlock ES, Haar JL (1983) The liver hemopoietic environment: I. Developing hepatocytes and their role in fetal hemopoiesis. Anat Rec 207(1):31-41. https://doi.org/10.1002/ar.1092070105

16. Abdel-Fatah AA (1992) Effect of tetracyclines on the development of the liver in chick embryos (Dissertation). Al-Azhar University, Egypt

17. Bruni C, Porter KR (1965) The fine structure of the parenchymal cell of the normal rat liver: I. General observations. Am J Pathol 46(5):691-755

18. Moule Y (1964) Cellular membranes in development. Academic Press Inc, New York

19. Johnson KE (1997) Histology and cell biology, 2nd edn. Williams and Wilkins, Baltimore

20. Al-Yousuf SA (1992) An atlas of cells ultrastructure. Doha Modern Printing Press, Doha

21. Burkitt HG, Young B, Heath JW, Wheater PR, Deakin PJ (1993) Wheater's functional histology: a text and colour atlas 6 th Edn. Churchill Livingstone, London

22. Han SS, Holmsted JV (1981) Human microscopic anatomy, 1st edn. McGrawHill Book Company, New York

23. Mahmoud SH (1994) Histological cytological and cyto-chemical studies of the effect of some cyanine days on some organs in mice (Dissertation) Alexandria University, Egypt

24. Farhoud HM (1998) Light and ultrastructural study of the developing testes of neonate albino rat after maternal use of haloperidol. N Egypt J Med $19(2): 12-23$

25. Hummdi LA (2012) Histopathological alterations in renal tubules of female rats topically treated with paraphenylen diamine. World Appl Sci J 16(16): 376-388

26. Moody DE, Reddy JK (1976) Morphometric analysis of the ultrastructural changes in rat liver induced by the peroxisome proliferator SaH 42-348. J Cell Biol 71(3):768-780. https://doi.org/10.1083/jcb.71.3.768

27. Ahmed EA (2000) Histological and ultra-structural studies on effect of (captopril) on some organs of albino swiss mice (Dissertation), Alexandria University, Egypt

28. Ayman E, Osman HE, Daghestani MH (2013) The effect of vitamin C administration on monosodium glutamate induced liver injury. An experimental study. Exp Toxicol Pathol 65(5):513-521

29. de Duve C (1959) Lysosomes, a new group of cytoplasmic particles. Subcell Part 60:128-159

30. Hassan FM, El-Banhawy MA, Mohaddal ME, Rahmy TR (1986) Lethality of pseudo Cerastes persicus field venom and the effect of its sublethal dose on the liver function of envenomated rats. Egypt J Biochem 4:120-148
31. Cotran RS, Kumar V, Stanley L (1995) Robbins' pathological basis of disease, 5th edn. W.B. Saunders, Philadelphia

32. Pfeifer U, Bannasch P (1986) On the problem of "hyaline protein droplets" in the cytoplasm of liver parenchyma cells. Light and electron microscopic studies after three-forths hepatectomy. Virchows Archiv B Cell Pathol 1(4): 365-388

33. Tuchweber B, Sieck R, Trost W (1979) Prevention by silybin of phalloidininduced acute hepatoxicity. Toxicol Appl Pharmacol 51(2):265-275. https:// doi.org/10.1016/0041-008X(79)90469-1

34. Abbasi S, Khattak SM, Malik S (2018) Protective effect of vitamin c on monosodium glutamate induced changes in the oviduct of rats. J Ayub Med Coll Abbottabad 30(4):588-591

35. Takano A, Shibayama Y, Nakata K (1984) The morphogenesis of the vacuolation of liver cells. Liver 4(2):97-104. https://doi.org/10.1111/j.16000676.1984.tb00913.x

36. Biondo-Simões MLP, Zammar GR, Fernandes RS, Biondo-Simões R, Mello FS, Noronha LD (2010) Obesity and abdominal wound healing in rats. Acta Cir Bras 25(1):86-92. https://doi.org/10.1590/50102-86502010000100018

37. Aldana L, de Mejia EG, Craigmill A, Tsutsumi V, Armendariz-Borunda J, Panduro A, Rincón AR (1998) Cypermethrin increases apo A-1 and apo B mRNA but not hyperlipidemia in rats. Toxicol Lett 95(1):31-39. https://doi. org/10.1016/S0378-4274(98)00013-7

38. Luty S, Latuszynska J, Halliop J, Tochman A, Obuchowska D, Przylepa E, Korczak E (1998) Toxicity of dermally applied alpha-cypermethrin in rats. Ann Agric Environ Med 5(2):109-116

39. Shibayama Y, Matsumoto K, Satoh M, Nakata K (1980) Pathogenesis of vacuolar degeneration of the hepatocyte. Significance of intrasinusoidal pressure elevation. Acta Hepatol Jpn 21(10):1283-1294. https://doi.org/10.2 957/kanzo.21.1283

40. Burkitt SP, Lowe JS, Young B (1996) Wheater's basic histopathology, 3rd edn. Churchill livingstone, London

41. Awad ZE (2004) Effect of haloperidol on the developing pancreas of the chick embryo. (Dissertation), Al-Azhar University, Egypt

42. Dixon M, Dixon B, Aparicio S, Loney D (1975) Experimental paracetamolinduced hepatic necrosis: a light-and electron-microscope, and histochemical study. J Pathol 116(1):17-29. https://doi.org/10.1002/path.1 711160104

43. Young BL, Lowe JS, Stevens A, Heath JW, Deakin PJ (2005) Wheatear's functional histology a text book and color atlas, 5 th edn. Churchill Livington, Edinburgh

44. Al-Ghamdi F (2017) Toxicity of Monosodium Glutamate on the liver of chick embryos and the effectiveness of pomegranate peel extract in reducing this toxicity (to show scientific miracles in the Quran and Sunnah). Life Sci J 14(9):37-60

45. Overstreet K, Costanza C, Behling C, Hassanin T, Masliah E (2002) Fatal progressive hepatic necrosis associated with lamotrigine treatment: a case report and literature review. Dig Dis Sci 47(9):1921

46. Giorgio M, Migliaccio E, Orsini F, Paolucci D, Moroni M, Contursi C, Pelliccia G, Luzi L, Minucci S, Marcaccio M, Pinton P, Rizzuto R, Bernardi P, Paolucci F, Pelicci PG (2005) Electron transfer between cytochrome $c$ and p66Shc generates reactive oxygen species that trigger mitochondrial apoptosis. Cell 122(2):221-233. https://doi.org/10.1016/j.cell.2005.05.011

47. Anindita R, Soeprobowati TR, Suprapti NH (2012) Potensi teh hijau (Camelia sinensis L.) dalam perbaikan fungsi hepar pada mencit yang diinduksi monosodium glutamat (MSG). Anat Fisiol 20(2):15-23

48. Hassan HA, El-Kholy WM, El-Sawi MR, Galal NA, Ramadan MF (2020) Myrtle (Myrtus communis) leaf extract suppresses hepatotoxicity induced by monosodium glutamate and acrylamide through obstructing apoptosis, DNA fragmentation, and cell cycle arrest. Environ Sci Pollut Res Int 27:1-11

\section{Publisher's Note}

Springer Nature remains neutral with regard to jurisdictional claims in published maps and institutional affiliations. 